\title{
Separation of stimulating catheters for continuous peripheral regional anesthesia during their removal - two case reports and a critical appraisal of the use of steel-coil containing stimulating catheters
}

This article was published in the following Dove Press journal:

Local and Regional Anesthesia

30 June 2015

Number of times this article has been viewed

\section{Thomas Wiesmann' \\ Pascal Wallot' \\ Laura Nentwig' \\ Alisha-Viktoria Beermann' \\ Hinnerk Wulf' \\ Martin Zoremba' \\ Turfa Al-Dahna' \\ Daphne Eschbach ${ }^{2}$ \\ Thorsten Steinfeldt ${ }^{1}$ \\ 'Department of Anesthesia and Intensive Care Medicine, University Hospital Marburg, Marburg, Germany; ${ }^{2}$ Department of Trauma, Hand and Reconstructive Surgery, University Hospital Marburg, Marburg, Germany}

\begin{abstract}
Purpose: Stimulating catheters are widely used for continuous peripheral nerve block techniques in regional anesthesia. The incidence of reported complications is somewhat similar to that for non-stimulating catheters. However, as many stimulating catheters contain a coiled steel wire for optimal stimulation, they may cause specific complications.

Clinical features: In this report, we present two cases of complicated removals of stimulating catheters. During both removals, a part of the metal wire was left "decoiled" next to the supraclavicular and interscalene plexus, respectively. The strategies used to determine steel wire localization and a description of the successful removal of these steel wires are included in this report.

Conclusion: Catheter separation and problems with residual metal wire components of stimulating catheters seem to be a rare but specific problem during removal. Anesthesiologists should strictly avoid catheter shearing during insertion, adhere to the manufacturer's instructions, and take care during catheter removal. Manufacturers should focus on technical solutions to avoid rare but relevant complications such as catheter tip decoiling and separation of stimulating catheters during removal.
\end{abstract}

Keywords: stimulating catheter, catheter separation, complication, peripheral nerve block, perineural catheter

\section{Introduction}

Continuous peripheral nerve block catheters are standard procedure for optimal pain control following orthopedic and traumatology procedures. The benefits of improved pain control, reduction in opioid medication use, and improved postoperative mobilization have been shown to outweigh the risk of nerve injury, local infection, or other potential side effects., ${ }^{1,2}$ Catheters are usually removed between the second and sixth postoperative day.

Instead of the insertion of conventional "plastic" catheters via a needle positioned next to the nerve, stimulating catheters might be beneficial to guarantee catheter positioning next to the nerve. ${ }^{1,3}$ For stimulation, catheters can be plugged into a nerve stimulator in order to conduct electricity within the insulated catheter sheath to the conducting tip, resulting in nerve stimulation when optimal placement is achieved. Most manufacturers use a stainless steel containing wire within a polyurethane sheath
Correspondence: Thomas Wiesmann Department of Anesthesia and Intensive Care Medicine, University Hospital Giessen and Marburg, Campus Marburg, Baldinger Strasse 35033 Marburg, Germany

$\mathrm{Tel}+49642 I 5869362$

Fax +49 642I 5865 97I

Email wiesmann@med.uni-marburg.de 
ending in a tip of coiled steel wire for optimal stimulation quality.

This special design of stimulation catheters can result in potentially harmful events during catheter removal. ${ }^{4}$ In this case report, we present two cases with complications during removal.

\section{Case I}

A 75-year-old woman (ASA II, body mass index 29) was scheduled for arthroscopic shoulder surgery due to subacromial impingement. She gave written consent to participate in a randomized controlled trial comparing the clinical effectiveness of supraclavicular and interscalene nerve block catheters for arthroscopic shoulder surgeries. Before the induction of general anesthesia, a supraclavicular nerve block catheter (stimulating continuous peripheral nerve block catheter, Arrow StimuCath, 18 G Tuohy needle, 20 G catheter, Teleflex Medical Germany, Kernen, Germany) was positioned under mild sedation according to the randomization result. Under aseptic conditions, ${ }^{5}$ in this case, a lateromedial approach was chosen under ultrasound guidance (in-plane approach) after visualization of the subclavian artery and the supraclavicular plexus. ${ }^{6}$ Percutaneous advancement of the $18 \mathrm{G}$ Tuohy needle resulted in a good needle tip position next to the plexus and a good stimulation result $(0.8 \mathrm{~mA} / 0.1 \mathrm{~ms})$ with a typical biceps response. After removal of the needle stylet, the stimulating catheter $(20 \mathrm{G})$ was inserted into the needle, connected with the nerve stimulator and carefully advanced to approximately $4.5 \mathrm{~cm}$ over the needle tip. No further needle repositioning or withdrawal of the catheter was performed. Finally, after successful stimulation results via the catheter, the indwelling catheter stylet was removed, followed by complete needle withdrawal. As the patient was participating in a clinical study unrelated to the issue of this case report, correct positioning of the catheter was documented, including a total time of 5 minutes between skin puncture and the beginning of sterile draping of the inserted catheter by our study assistant. The postoperative course was without any relevant complications under a continuous flow of ropivacaine $0.2 \%$ (start flow $4 \mathrm{~mL} / \mathrm{h}$, at first postoperative day 1 reduction to $2.5 \mathrm{~mL} / \mathrm{h}$ ). Initial numbness after a start bolus of $10 \mathrm{~mL}$ ropivacaine $0.2 \%$ was resolved on the first postoperative day. Catheter removal was scheduled for the second postoperative day. After removal of the sterile draping, the responsible pain nurse withdrew the catheter using gentle traction but stopped immediately when she noticed catheter separation (see Figure 1). Accordingly, she informed the responsible consultant, who unfortunately

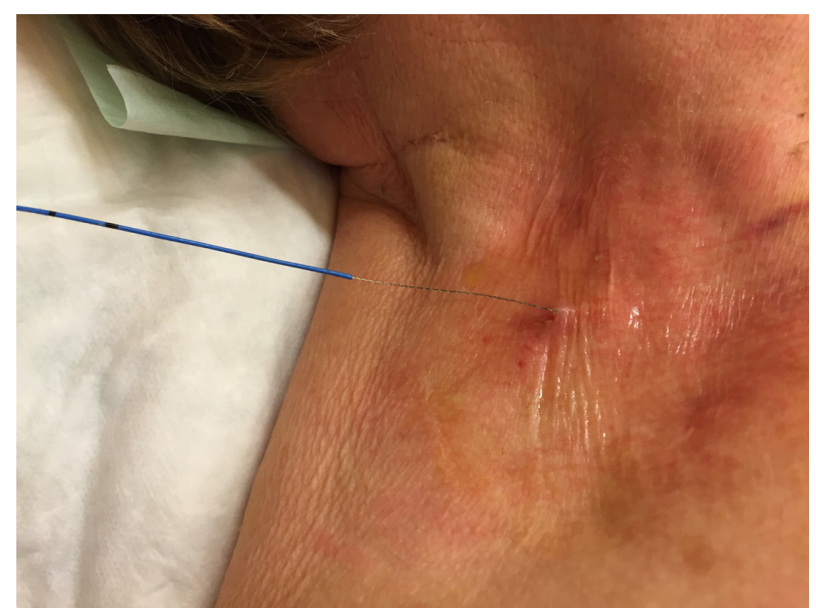

Figure I Indwelling steel wire and separated polyurethane catheter at the supraclavicular plexus.

could not remove the indwelling residual steel wire. Notably, the patient complained of pain during gentle traction via the residual wire. Another removal attempt was performed in our post anesthesia care unit under standard monitoring and mild analgosedation using fentanyl $0.1 \mathrm{mg}$ intravenously. Under ultrasound guidance, the residual wire was traced backwards to its final position next to the supraclavicular plexus. Traction of the wire resulted in tissue movements next to the plexus fascia and patient discomfort. The completely removed polyurethane component was visually checked and showed no signs of incisions, kinking or otherwise expected damage. Under sterile conditions, the proximal polyurethane catheter component was cut away. In another attempt, the residual wire was threaded through a $16 \mathrm{G}$ intravenous catheter (Braunuele, B Braun Medical, Melsungen, Germany) and then the catheter was advanced retrogradely through the skin until resistance occurred ( $\sim \mathrm{cm}$ beneath the skin). Another attempt to remove the indwelling wire through this artificial tunnel under forced traction unfortunately failed again.

In a second attempt, sterile saline $0.9 \%$ was injected via the indwelling intravenous catheter with the hope of removing suspected adhesions or resolving catheter kinking, "pigtailing" or coiling phenomena. However, this approach failed again. Sterile draping was applied and a computed tomography (CT) scan of the neck was scheduled to further investigate these complications. In the CT scan (see Figure 2), the residual wire was shown starting from beneath the skin lying backwards and ending next to the supraclavicular plexus (but not within the fascicles) without relevant kinking or coiling. Thereafter, our local ear, nose, and throat (ENT) specialists were consulted to discuss further options. 


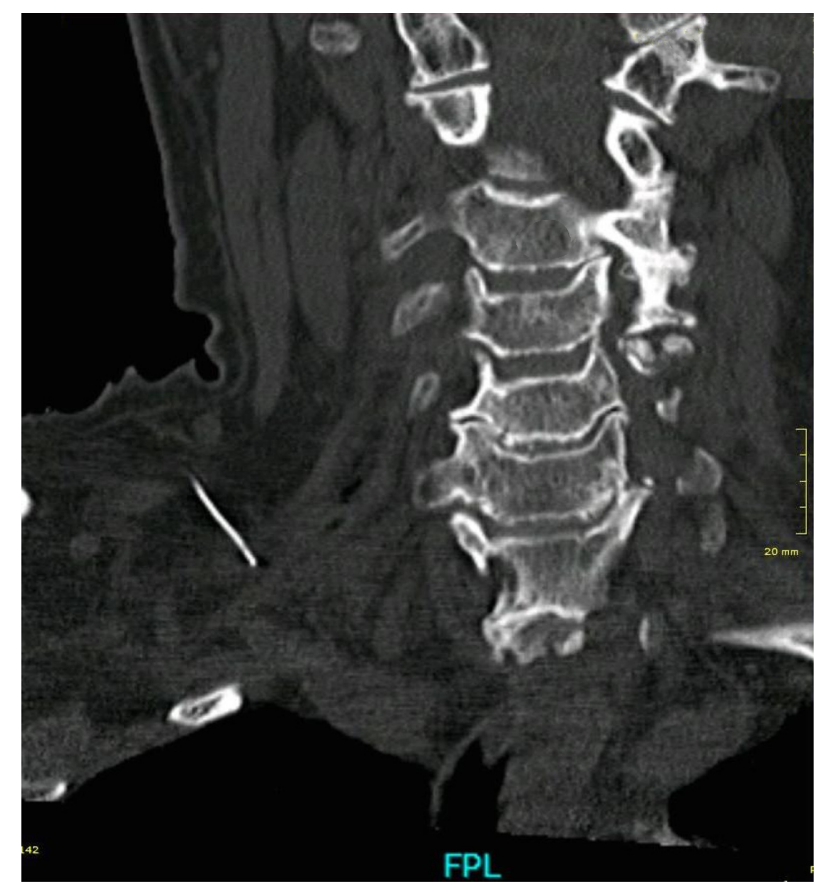

Figure 2 Computed tomography scan (frontal view) of residual metal wire.

After a thorough discussion of this topic with the orthopedic consultant, and within this framework, the patient gave consent for surgical removal by a neurosurgeon and an ENT surgeon who specializes in neck dissections, performed under general anesthesia. After the induction of general anesthesia and complete muscular relaxation in the afternoon, the ENT surgeon performed forceful traction again. The complete residual wire, including the complete characteristic steel wire tip, was successfully removed during this last attempt. Therefore, a surgical incision was not performed. After the termination of anesthesia, the patient had no neurological sequelae or pain at the insertion site or close to the plexus. She was discharged home on the following day.

\section{Case 2}

In the second case report, a 32-year-old male patient (ASA I, body mass index 25) presented who was scheduled for arthroscopic shoulder surgery including subacromial decompression and arthroscopic resection of the acromioclavicular joint. After informed consent, the patient received an interscalene nerve block catheter under mild analgosedation (0.2 mg fentanyl intravenously). Under sterile conditions and ultrasound guidance using an out-of-plane approach, a Tuohy needle was inserted next to the interscalene plexus with a needle depth of $4 \mathrm{~cm}$. After successful stimulation with $0.8 \mathrm{~mA}$ (0.1 msec), a stimulating catheter (Stimucath, 18 G Tuohy needle, $20 \mathrm{G}$ stimulating catheter, Teleflex Medical Germany) was inserted and conveniently positioned under good stimulation quality. No needle or catheter corrections were needed. After removal of the needle and sterile draping of the catheter, the catheter (catheter depth $8.5 \mathrm{~cm}$ ) was loaded with $10 \mathrm{~mL}$ ropivacaine $0.2 \%$. Continuous ropivacaine application via the catheter was performed using an AmbIt pump (Teleflex Medical Germany) with a flow rate of $4 \mathrm{~mL} / \mathrm{h}$ and a bolus function of $4 \mathrm{~mL}$ ropivacaine $0.2 \%$. Catheter removal was scheduled for the second postoperative day according to the patient's wishes after an uneventful postoperative course.

Our pain service tried to remove the catheter on the scheduled third day but described difficulties with removing the catheter, particularly regarding the distal catheter wire which was entangled within the subcutaneous tissue. The removed polyurethane catheter sheath showed no signs of defect upon visual inspection. After contacting a consultant in our department, several positioning maneuvers were tried. Additionally, as the suspected catheter end was indeed palpated in the subcutaneous tissue, an attempt at local massage was performed. No further diagnostic approaches (eg, ultrasound, CT scanning) were performed. After several laborious trials, the stainless steel wire including the wire tip became unfastened and was removed entirely. The patient showed neither neurological sequelae in the respective extremity nor further local complications at the catheter insertion site.

\section{Discussion}

Complications after the insertion of peripheral regional anesthesia catheters are rare and are usually not related to a defect in the catheter material used. ${ }^{1,7}$ Typical equipment problems with regional anesthesia catheters during their removal are most commonly due to either knotted or sheared catheters. ${ }^{4,8,9}$ In the worst case, the catheter material might break apart and result in residual catheter fragments within the tissue. ${ }^{10}$ After the second case within a few weeks in our department, we performed an intensive literature search and found a case series of five patients published by Clendenen et al in $2010 .{ }^{4}$ In their report, stimulating catheters from the same manufacturer showed similar signs of catheter separation. Interestingly, they used similar approaches to remove the indwelling steel wire, including retrograde positioning of an intravenous catheter using the Seldinger technique. Additionally, Brenier et al published a case report of a separated stimulating catheter by the same manufacturer resulting in surgical removal of the indwelling residual catheter wire. ${ }^{11}$

Nerve block catheter shearing is a rare complication mostly caused by iatrogenic problems. Besides shearing, catheter knotting is another not uncommonly documented 
complication that mostly occurs when catheter removal is intended following an advancement of the catheter for a long distance over the needle. The consequences of this are catheter looping, kinking, and occasionally knotting. ${ }^{12}$ Nevertheless, in the present cases, the polyurethane layers revealed no signs of knotting or kinking as an explanation for these complications. This was also ruled out using ultrasound examination as well as CT scanning.

Shearing of regional anesthesia catheters most likely occurred during needle repositioning trials while the indwelling catheter was already advanced beyond the needle tip. Undeniably, the procedures in our documented cases were all performed by two experienced anesthesiologists without the need for any needle advancement or catheter retraction after initial catheter insertion. The intact outer polyurethane layer of the catheter underlines this fact.

Clendenen et a ${ }^{4}$ discuss the possibility of relevant tissue reaction and subsequent adherence of the catheter. However, in both of our cases, catheters were not used for prolonged periods, making this possibility unlikely.

The special design of the StimuCath stimulating catheter set consists of an insulated Tuohy needle for stimulation and a stimulating catheter with a stainless steel wire tip and a metal wire needle stylet. After successfully positioning the stimulating catheter via a Tuohy needle, the catheter stylet must be removed before the Tuohy needle is removed. Otherwise, "creating an external artificial resistance to catheter stylet removal can result in the occurrence of a 'pigtail' at the distal end of the catheter due to tension on the stainless steel coil" (as theorized by Clendenen et al). ${ }^{4}$ In our first presented case in this report, the catheter stylet was removed before needle withdrawal, thus this theory is not applicable in the first case. With regard to the second case, we cannot rule out the exact process used during catheter stylet and needle removal as no further details regarding needle positioning were noted in the patient's report.

Finally, the specific wound metal tip (see Figure 3) might be more vulnerable to entangling with surrounding fascia structures (eg, prevertebral fascia, scalenus muscle fascia) compared with the smooth polyurethane tips on nonstimulating catheters. This might increase the risk of catheter separation with the application of gentle traction during removal. Interestingly, the majority of case reports with this catheter model deal with interscalene or supraclavicular nerve blockade. One might speculate as to whether this complication is seen more often in these locations or if it is due to the fact that interscalene catheter techniques are more common than continuous sciatic or femoral nerve blockades. On the

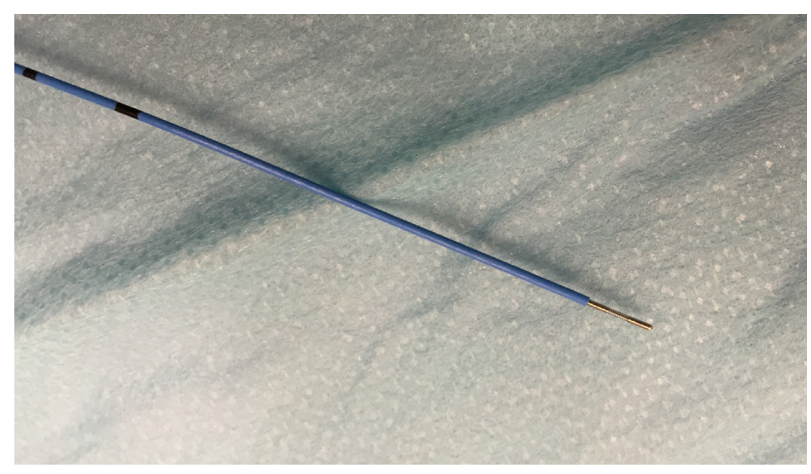

Figure 3 Catheter tip (Stimucath, Teleflex Germany, Kernen, Germany).

other hand, postoperative mobilization might result in more catheter shearing stress in upper extremity compared with lower extremity nerve blocks, resulting in a predisposition for this complication.

Concerning both of these cases, the manufacturer was contacted. In addition, in accordance with German laws, a report was sent to the responsible governmental authority reporting the issues.

Lastly, we assume that a manufacturing problem or a problem with the catheter architecture itself might be another explanation for these repeatedly occurring problems. Discussions with experienced anesthesiologists using the same catheter design uncovered several cases of catheter separation in other institutions as well. As we perform more than 1,000 continuous peripheral regional anesthesia procedures per year using stimulating catheters, the incidence of two cases in 1 year is a rare complication. However, in both cases, this complication can lead to unwanted painful catheter removal, exposure to radiation (CT scan), the need for general anesthesia and a planned surgical intervention, making this complication a relevant issue.

We recommend the following diagnostic and therapeutic approach before further attempts to remove residual catheter fragments are performed. First, an ultrasound examination should be performed to identify the indwelling catheter parts including their relation to plexus structures. In doubtful cases, a CT scan might improve results of tip identification. In subcutaneous catheter wire position, local massage and positioning maneuvers might de-entangle the catheter fragment as described above. In deep indwelling catheters next to neural structures, a discussion with a surgeon should be initiated regarding the best approach for removal (forced traction under sedation, surgical exposure). Patient consent must be obtained before invasive procedures for catheter removal. We strongly recommend thorough written documentation of the steps performed to avoid medicolegal problems. 
We are unable to rule out the exact mechanisms of catheter separation in these two reported cases. Potential mechanisms have been described by Clendenen et al and others and are discussed above. Besides (unlikely) manufacturing problems, the design of the catheter containing a steel wire might predispose to catheter separation compared with a monobloc polyurethane catheter design. Combined with potential operator errors by the respective anesthetists performing the catheter insertion, complications might arise that are exclusively related to this specific catheter style. However, from the patient's point of view, total prevention of this complication is more important than the exact mechanism of the complication itself. Thus, the safest approach to avoid catheter separation is to rely on a monobloc polyurethane catheter design combined with an insertion technique not associated with potential risks of shearing or separation.

Therefore, we hope that the manufacturers of stimulating catheters will improve the catheter design to avoid coiled steel wires, as there is now an obviously demonstrated separate risk factor for difficult catheter removals. Beside this, it is pivotal that anesthesiologists are well trained in the specific catheter types used in their own department, including offsite training for correct use according to the manufacturer's instructions.

\section{Disclosure}

TS has received speaker fees from Teleflex Medical, Vygon, B Braun Medical. HW has received speaker fees from Teleflex Medical, Vygon, B Braun and Sinthetica as well as financial funding for the study as mentioned above. The other authors have no conflicts of interest to disclose.

\section{References}

1. Ilfeld BM. Continuous peripheral nerve blocks: a review of the published evidence. Anesth Analg. 2011;113(4):904-925.

2. Neuburger M, Breitbarth J, Reisig F, Lang D, Büttner J. Komplikationen bei peripherer Katheterregionalanästhesie. Untersuchungsergebnisse anhand von 3491 Kathetern. [Complications and adverse events in continuous peripheral regional anesthesia Results of investigations on 3,491 catheters]. Anaesthesist. 2006;55(1):33-40. German.

3. Kill C, Steinfeldt T. Stimulationskatheter als neues Prinzip in der täglichen Praxis. [Stimulating catheters for regional anesthesia: considerations in routine clinical use]. Anasthesiol Intensivmed Notfallmed Schmerzther. 2006;41(7-8):476-481. German.

4. Clendenen SR, Robards CB, Greengrass RA, Brull SJ. Complications of peripheral nerve catheter removal at home: case series of five ambulatory interscalene blocks. Can J Anesth. 2010;58(1):62-67.

5. Kerwat K, Schulz-Stübner S, Steinfeldt T, et al. [Hygiene recommendations for regional anesthesia - an updated recommendation]. Anasthesiol Intensivmed Notfallmed Schmerzther. 2015;56:34-40. Available from: http://www.ak-regionalanaesthesie.dgai.de/empfehlungenlinks/empfehlungen/doc_details/86-hygieneempfehlungen-fuer-dieregionalanaesthesie.html. Accessed May 13, 2015.

6. Steinfeldt T, Schwemmer U, Volk T, et al. Nerve localization for peripheral regional anesthesia. Recommendations of the German Society of Anaesthesiology and Intensive Care Medicine. Anaesthesist. 2014; 63(7):597-602.

7. Neal JM, Gerancher JC, Hebl JR, et al. Upper extremity regional anesthesia: essentials of our current understanding, 2008. Reg Anesth Pain Med. 2009;34(2):134-170.

8. Lee BH, Goucke CR. Shearing of a peripheral nerve catheter. Anesth Analg. 2002;95(3):760-761.

9. Guerci P, Novy E, Guibert J, Vial F, Malinovsky JM, Bouaziz H. Cisaillements accidentels de cathéters périnerveux lors de poses échoguidées. [Inadvertent peripheral nerve catheter shearing occurring during ultrasound guidance]. Ann Fr Anesth Reanim. 2013;32(5):364-367. French.

10. Despond O, Kohut GN. Broken interscalene brachial plexus catheter: surgical removal or not? Anesth Analg. 2010;110(2):643-644.

11. Brenier G, Salces A, Maguès JP, Fuzier R. Peripheral nerve catheter entrapment is not always related to knotting. Can JAnesth. 2010;57(2): $183-184$.

12. Offerdahl MR, Lennon RL, Horlocker TT. Successful removal of a knotted fascia iliaca catheter: principles of patient positioning for peripheral nerve catheter extraction. Anesth Analg. 2004;99(5):1550-1552.

\section{Publish your work in this journal}

Local and Regional Anesthesia is an international, peer-reviewed, open access journal publishing on the development, pharmacology, delivery and targeting and clinical use of local and regional anesthetics and analgesics. The journal welcomes submitted papers covering original research, basic science, clinical studies, reviews \& evaluations, guidelines, expert opinion and commentary, case reports and extended reports. The manuscript management system is completely online and includes a very quick and fair peer-review system, which is all easy to use. Visit http://www.dovepress.com/testimonials.php to read real quotes from published authors. 